\title{
COOPERAÇÃO E INOVAÇÃO NA GESTÃO PÚBLICA: 0 CASO DA SAÚDE
}

\author{
Por Ana Paula Paes de Paula \\ Professora da UFMG \\ E-mail: appaula@face.ufmg.br
}

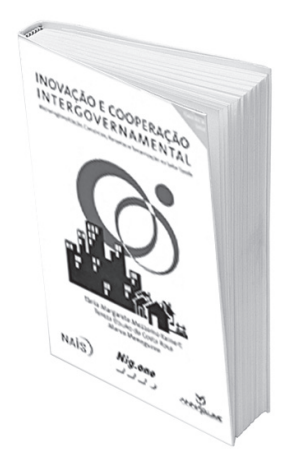

\section{INOVAÇÃO E COOPERAÇÃO INTERGOVERNAMENTAL: MICRORREGIONALIZAÇÃO, CONSÓRCIOS, PARCERIAS E TERCEIRIZAÇÃO NO SETOR SAÚDE}

De Tânia Margarete Mezzomo Keinert, Tereza Etsuko da Costa Rosa e Marco Meneguzzo

São Paulo: Annablume, 2006. 222 p.

Neste livro, os autores buscam discutir o novo papel dos governos subnacionais na formulação e implementação de políticas públicas de saúde no contexto do processo de descentralização no Brasil. Ao analisar experiências diferenciadas empreendidas com a participação das Secretarias Estaduais de Saúde em cinco estados da Federação, os autores mapeiam as "melhores práticas" que podem subsidiar a elaboração de estratégias de intervenção que tornem efetivo o papel de coordenador e articulador do nível estadual na condução e organização de serviços de saúde nos níveis microrregional e regional.

O trabalho se reveste de especial importância quando consideramos que um dos maiores desafios do Sistema Único de Saúde (SUS) é o aperfeiçoamento de seu modelo ins- titucional, tendo em vista a forte presença decisória do Executivo, que se sobrepõe aos controles legislativo e social. A instituição das Comissões Intergestores Tripartites (CITs) foi uma tentativa de solução cooperativa para dar conta desse problema, na medida em que retirou do governo federal a possibilidade de estabelecer unilateralmente as regras do jogo do SUS, dando voz às instâncias estaduais e municipais. O mesmo ocorreu no caso das Comissões Intergestores Bipartites (CIBs), nas relações entre estados e municípios, tendo em vista a necessidade de cooperação entre as microrregiões para a organização de serviços de saúde.

Nesse sentido, os autores resgatam experiências de parceria entre as partes componentes do pacto federativo, de modo que as noções de cooperação intergovernamental e de solidariedade territorial e social se tornam fundamentais na busca de alternativas de redesenhos institucionais e de estratégias de gestão. Essas experiências podem ser consideradas inovadoras na medida em que constroem uma proposta de regionalização da gestão das políticas de saúde com efetiva participação do nível estadual em parceria com os governos municipais. A obra está organizada em três partes, destacando em cada uma delas os seguintes pontos: processos de regionalização em situações nas quais as características demográficas, epidemiológicas e socioeconômicas são homogêneas e propiciam ganhos de escala nas políticas de saúde; processos de planejamento intersetorial e articulação microrregional baseados na delegação de prestação de serviços; 
e processo de descentralização e de parcerias público-privadas na Itália, que foi referência para a construção do SUS no Brasil.

Na primeira parte, são relatadas as experiências do Paraná, do Ceará, do Mato Grosso e de São Paulo. No Paraná, a Secretaria Estadual da Saúde incentivou a criação de consórcios, e a escassez de recursos humanos e infraestrutura nos pequenos municípios predispôs essas cidades a aderirem a essa proposta. Ainda se discute se o papel dos consórcios é o de gestor da microrregião ou de mero prestador de serviços, pois a CIB não tem funcionado de forma a incentivar mudanças, mas a experiência se notabiliza por sua adesão à filosofia "cidades saudáveis" e às iniciativas intersetoriais. No Ceará, ocorreu uma relação de cooperação entre estados e municípios que propiciou uma inovação: o sistema microrregional de serviços de saúde, que conta com CIBs microrregionais e se destaca pelo avanço no que se refere ao controle social.

No Mato Grosso, a Secretaria da Saúde avançou ao aderir aos princípios do SUS, e também ao incentivar a constituição de consórcios intermunicipais de saúde, mas sem aderir a um modelo único, atendendo as necessidades e problemas de cada região. Em São Paulo, a experiência das Direções Regionais de Saúde (DIRs) exemplifica as dificuldades enfrentadas na cooperação entre estado e municípios, como o despreparo de recursos humanos para atuar nessa nova conjuntura, a indefinição do papel de cada ente federado e a influência do porte do município.

$\mathrm{Na}$ segunda parte, são discutidos casos de delegação de prestação de serviços nos estados da Bahia e de São Paulo. Na Bahia, a experiência, que inclui a gestão privada de unidades hospitalares do estado, não é uma privatização no sentido estrito, pois o estado continua proprietário delas, exercendo seu controle por meio de contratos de gestão. Na visão dos autores, a experiência é positiva, mas ainda não é possível avaliar se é realmente mais eficiente que a gestão totalmente pública. Outro capítulo discorre sobre a implantação do sistema de regulação da saúde da Bahia, que foi realizado em sintonia com o processo de descentralização administrativa, regionalização e redefinição das atribuições do estado e dos municípios. Em São Paulo, o caso relatado é o de 15 hospitais públicos cujas obras estavam paralisadas e que são agora geridos por organizações sociais. Baseados em depoimentos, os autores concluem que a experiência representa uma inovação por realizar a gestão da coisa pública com critérios de eficácia e eficiência da gestão privada.

$\mathrm{Na}$ terceira parte, é apresentada a experiência italiana. Um dos capítulos aborda os reflexos do novo cenário econômico-financeiro nas estratégias regionais de saúde, em especial para lidar com o déficit, o que é de particular interesse para o caso do SUS, pois enfrentamos uma crise do federalismo fiscal que afeta o estado e os municípios. Discute também a recentralização, voltada para a redução da fragmentação dos sistemas administrativos públicos e a necessidade de reforçar a capacidade de governança em relação aos diversos atores sociais e institucionais. O capítulo seguinte trata das parcerias público-privadas instruídas pela nova administração pública, apresentando as vantagens das terceirizações realizadas, embora os autores admitam que os resultados dessa nova estratégia ainda não tão são significativos.

Sente-se falta de um capítulo conclusivo no qual os autores discutissem de uma maneira integrada as experiências analisadas, elaborando aportes teóricos para futuras pesqui- sas. As mudanças introduzidas pela nova administração pública também poderiam ter sido objeto de uma análise crítica, pois não há uma discussão sobre a inserção da lógica privada no setor público, que é passível de questionamentos. No entanto, embora os autores considerem a utilização de critérios da gestão privada uma inovação, em outros momentos eles se mostram alinhados com outras concepções de inovação, discutidas por Peter Spink na obra de Jacobi e Pinho Inovação no campo da gestão pública local (Rio de Janeiro: Editora FGV, 2006). Apesar disso, como não discutem conceitualmente a questão da inovação, não chegam a abordar a distinção de Spink entre as "melhores práticas", que leva a julgamentos normativos sobre as ações que seriam corretas e a "abordagem das inovações", que enfatiza a construção de vínculos discursivos entre pessoas e instituições para mudar as práticas públicas.

Por outro lado, um posicionamento mais crítico sobre a terceirização seria desejável, pois análises mais recentes apontam que ela pode causar fragilidade na capacidade de fiscalização e regulação do poder público. Um artigo publicado na Folha de $S$. Paulo (16/01/2007) sobre as obras do metrô sugere que o recurso à terceirização pode ter sido uma das causas do acidente ocorrido nas obras da Linha 4. Estas limitações, porém, não reduzem o valor da obra que é, sem dúvida, uma referência indispensável para os pesquisadores, dada a qualidade, abrangência e profundidade da pesquisa na qual se apóia, a escassez de publicações na área e a importância que a temática tratada assume na atual configuração dos governos subnacionais. Além disso, a diversidade e a riqueza das experiências catalogadas e analisadas, bem como a clareza do texto, fazem desse um livro de agradável leitura. 